\section{THE INFLUENCE OF DEMAGNETIZATION ON THE MAGNETIC AFTER-EFFECT OF CO-Cr MICROSTRUCTURES}

Hans te Lintelo, Wim Streekstra, Cock Lodder.

Mesa Reasearch Institute, University of Twente, P.O. box 217, 7500 AE Enschede, the Netherlands.

\section{Introduction.}

Time dependence of magnetic storage media is of practical interest in long term stability and high frequency writing. For $\mathrm{Co}-\mathrm{Cr}$ media with a perpendicular effective magnetic anisotropy $\left(\mathrm{K}_{\mathrm{eff}}>0\right)$ the remanent magnetization is found to decay quasilogarithmic with time $[1,2]$ and to depend on the demagnetizing field $\mathrm{H}_{\mathrm{d}}$. A dependence on $\mathrm{H}_{\mathrm{d}}$ was observed experimentally by Lottis et al. [2] who measured the decay in readback signal of a written bit pattern. However the relation with the demagnetization factor $\mathrm{N}_{\mathrm{z}}$ was not quantified.

Therefore in this paper the lime dependence of asTherefore in this paper pputtered and paterned $\mathrm{Co} C r$ is discussed. The patterned $\mathrm{CoCr}$ has a structure as in [2] (see figure 1), and exhibits a $N_{z}<1, N_{z}$ was obtained experimentally by VSM and torque measurements, as described in [3]. The influence of a theonetically calculated $\mathrm{N}_{\mathrm{z}}$ on the time dependence of the remanent magnetization is simulated.

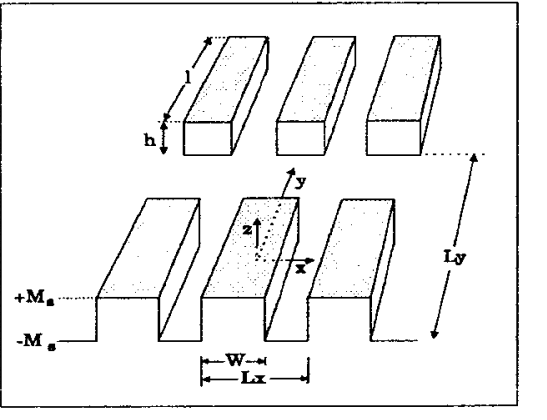

figure 1 .

Dimensions and notation of the $\mathrm{Co}$-Cr pattern.
Experimental

Co-Cr was RF sputtered under optimized conditions [4]. The pattern was obtained by ion-beam etching, leaving the intrinsic magnetic properties unaffected. However the demagnetization difference influences the shearing of the hysteresis curve (figure 2). For time dependent measurements the films were initially saturated to minus $1000 \mathrm{kA} / \mathrm{m}$ and then the field was set within 12 seconds to a constant value. The magnetic moment was monitored for 1 hour. The measurements were performed at room temperature. The most relevant magnetic properties are listed in table 1.

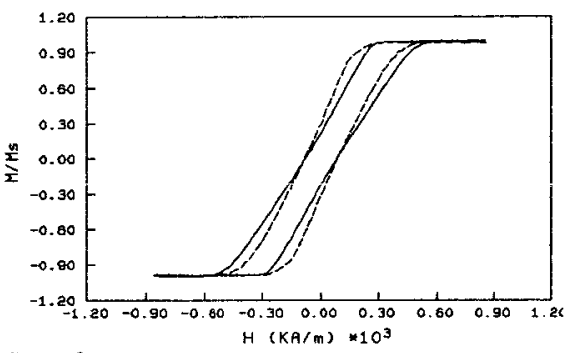

figure 2. $H(\mathrm{KA} / \mathrm{m}) * 10^{3}$

Perpendicular hysteresis curves of $140391-10$

(solid line) and 140391.9 (dashed line)
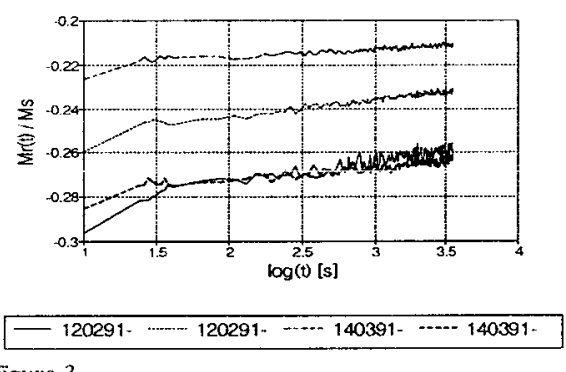

Remanent decay of $\mathrm{Co}$-Cr showing the influence of $H_{d}$.

Results.

In figure 3 the time dependence of the normalized remanent magnetization $M_{r} / M_{s}$ is shown. Samples nr. 10 exhibit slower decays. This effect is due to a lower demagnetizing field $\left(\mathrm{H}_{d}=\mathrm{N}_{\mathrm{z}} \mathrm{M}_{\mathrm{r}}\right)$. The absolute values of the samples nr. 10 are lower because of their lower $M_{r}$ (see figure 2).

In figure 4 the decrease per 'e-cade' of time $S$ is given as a function of the applied field. The as-sputtered sample shows an almost constant behaviour (open squares). The patterned sample (filled squares) slowly decreases towards the value of the open squares. Note that there is no maximum value of $\mathbf{S}$ near coercivity. as is observed in in-plane media, but that a small increase can be observed around $-50 \mathrm{kA} / \mathrm{m}$.

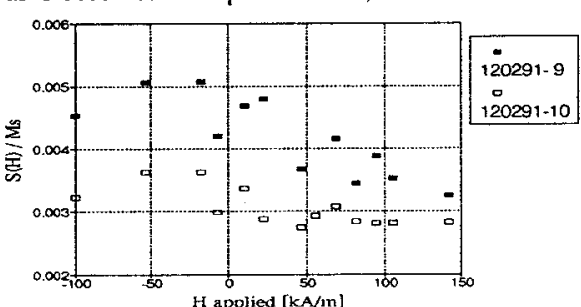

figure 4 .

Magnetic after-effect as a function of $H_{\text {app }}$

Simulation.

The remanent decay can be simulated using the modified Neel model [1], by inserting $N_{z}$ in the demagnetizing term. In figure 5 an example is given which clearly features a slower decay with decreasing $\mathrm{N}_{\mathrm{z}}$. In this figure also two 'time windows' regions, as observed in [5], can be defined. When calculating the $\mathrm{N}_{\mathrm{Z}}$ of our pattemed samples $\left(\mathrm{N}_{Z} \mathrm{P}\right)$ and the written bit pattern $\left(\mathrm{N}_{\mathrm{Z}} \mathrm{b}\right)$ in ref. 2 , it can be concluded that $\mathrm{N}_{\mathrm{z}}{ }^{\mathrm{b}}<\mathrm{N}_{\mathrm{z}} \mathrm{P}<1$ (the calculation is based on multiple Fourier series [6] and the patter having equal dimensions). These results support the conclusions in reference 2 that the slower decay in signal with time decreases with increasing bit density.

\begin{tabular}{|l|c|c|c|c|c|c|c|c|c|c|}
\hline $\begin{array}{c}\text { Sample } \\
\text { name }\end{array}$ & $\begin{array}{c}\mathrm{t} \\
{[\mathrm{nm}]}\end{array}$ & $\begin{array}{c}\mathrm{Ms} \\
{[\mathrm{kA} / \mathrm{m}]}\end{array}$ & $\begin{array}{c}\mathrm{Mr} \\
{[\mathrm{kA} / \mathrm{m}]}\end{array}$ & $\mathrm{Nz}$ & $\begin{array}{c}\mathrm{K1} \\
{[\mathrm{kJ} / \mathrm{m} 3]}\end{array}$ & $\begin{array}{c}\mathrm{Hc} \\
{[\mathrm{kA} / \mathrm{m}]}\end{array}$ & $\begin{array}{c}\mathrm{Lx} \\
{[\mu \mathrm{m}]}\end{array}$ & $\begin{array}{c}\mathrm{Ly} \\
{[\mu \mathrm{m}]}\end{array}$ & $\begin{array}{c}\mathrm{W} \\
{[\mu \mathrm{m}]}\end{array}$ & $\begin{array}{c}1 \\
{[\mu \mathrm{m}]}\end{array}$ \\
\hline $140391-9$ & 430 & 532 & 164 & 0.83 & 200 & 86 & 2 & 20 & 1 & 5 \\
\hline $140391-10$ & 430 & 532 & 119 & 1 & 200 & 83 & \multicolumn{5}{|c|}{ as-sputtered } \\
\hline $120291-9$ & 430 & 382 & 125 & 0.91 & 111 & 64 & 2 & 20 & 1 & 5 \\
\hline $120291-10$ & 430 & 382 & 79 & 1 & 111 & 66 & \multicolumn{5}{|c|}{ as-sputtered } \\
\hline
\end{tabular}

References.

[1]. D. Lottis R. White and E. Dan Dahlberg, J. Appl. Physics 67 (1990), pp. 5187.

[2] D.K. Lottis, E. Dan Dahlberg, J.A. Christner, J.I. Lee, R.L. Peterson and R.M. White, J. de Phys. C8 sup. nr 12 (1988), pp. 1989.

I. J. Eopma, J. Magn.Magn.Mat. 115 (1992), pp. 333

[4]. T. Wielinga and J.C. Lodder, IEEE Trans. Magn. MAG. vol 20 (1984), pp. 57.

55. Bucknell C Webb, S. Schultz and S. B. Oseroff, J. Appl. Physics 63 (188), pp. 2923

[6]. J. Kaczer and L. Murtinova, Phys. stat. sol. (a) 23, (1974), pp. 79 